\title{
Bimbingan Teknis K3 (Kesehatan dan Keselamatan Kerja) Konstruksi pada Era Normal Baru di Kota Kendari
}

\author{
Ainussalbi Al-Ikhsan*1, Arman Faslih², Muhammad Zakaria Umar³, La Ode Abdul Rachmad Sabdin", \\ Abdi Juryan Ladianto5, Sachrul Ramadan' \\ 1,2,3,4,5,6Program Studi D3 Teknik Arsitektur, Program Pendidikan Vokasi, Universitas Halu Oleo \\ *e-mail: ainussalbi_ikhsan@uho.ac.id¹, armanvokasi@gmail.com², zakariaumar@uho.ac.id³, \\ sabdinrachmad@gmail ${ }^{4}$, abdijuryanladianto@gmail.com ${ }^{5}$,Sachrul.ramadan_ft@gmail.com6
}

\begin{abstract}
This devotion was carried out at RT 05 and RT 06, Jl. Chairul Anwar, Lorong Durian, Wuawua Village, Wuawua District, Kendari City. This service is aimed at introducing personal protective equipment to builders. This service uses extension methods and practices. This dedication concluded that the builder's knowledge increased both before and after technical guidance because the post-test score was higher than the pre-test score.
\end{abstract}

Keywords: personal protective equipment, occupational Health and Safety, builders

\begin{abstract}
Abstrak
Pengabdian ini dilaksanakan di RT 05 dan RT 06, Jl. Chairul Anwar, Lorong Durian, Kelurahan Wuawua, Kecamatan Wuawua, Kota Kendari. Pengabdian ini ditujukan untuk memperkenalkan APD kepada para tukang bangunan. Pengabdian ini menggunakan metode penyuluhan dan praktik. Pengabdian ini disimpulkan bahwa pengetahuan tukang bangunan meningkat baik sebelum dan sesudah bimbingan teknis karena karena nilai postes lebih tinggi dibandingkan dengan nilai prates.
\end{abstract}

Kata kunci: Alat pelindung diri, kesehatan dan keselamatan kerja, tukang bangunan

\section{PENDAHULUAN}

Dunia konstruksi di Indonesia telah memasuki pasar global sehingga dituntut untuk mempunyai standar kualitas yang jelas (Ernawati, 2010). Dunia konstruksi identik dengan bangunan dan kegiatannya dilaksanakan di tempat kerja yang melibatkan tenaga kerja (Bahri, dkk., 2017 \& Ernawati, 2010). Tenaga kerja bisa dikategorikan sebagai sumber kecelakaan kerja. Dahulu, para ahli menggangap bahwa kecelakaan kerja berasal dari para pekerja yang tidak tepat dalam bekerja. Namun, pada saat ini kecelakaan kerja didapatkan dari faktor manajemen (Bahri, dkk., 2017). Di periode ini, setiap perusahaan mana pun mempunyai prinsip-prinsip manajemen yaitu berbiaya rendah dan bebas kecelakaan. Hal-hal inilah dapat ditempuh dengan perlindungan keselamatan dan kesehatan kerja. Pengetahuan dan keterampilan tenaga kerja terhadap perlindungan keselamatan dan kesehatan kerja cenderung rendah sehingga menimbulkan suatu tindakan yang tidak aman dalam bekerja (Hardianingtyas, 2011).

Keadaan ini bukan hanya terjadi di Indonesia tetapi juga di negara-negara lain. Tenaga kerja perlu dilindungi karena merupakan modal usaha yang perlu dijaga dan sesuai dengan aturan perundang-undangan (Departemen Pekerjaan Umum, Tanpa Tahun). Pada umumnya, para pekerja bangunan di Indonesia mempunyai kompetensi otodidak. Para pekerja bangunan tidak pernah mengikuti pelatihan khusus terkait aspek K3 (Kesehatan dan Keselamatan Kerja) sehingga kurang sadar melengkapi diri (Murtinugraha \& Anisah, 2019). Sampai dengan saat ini, bidang konstruksi masih menjadi penyumbang angka kematian terbesar akibat kerja sehingga dibutuhkan perhatian khusus agar dapat dikendalikan (Murti, 2015). Kecelakaan kerja berkaitan erat dengan lingkungan sosial, kecerobohan manusia, tindakan tidak aman, kecelakaan, dan cedera. Dari kelima hal tersebut bahwa 88 persen dari kecelakaan kerja disebabkan oleh pekerja, 10 persen pekerjaan, dan 2 persen takdir Tuhan (Murti, 2015; Woodside \& Kocurek, 1951).

Kecelakaan dan penyakit akibat kerja bisa dikendalikan dengan menggunakan sistem manajemen K3 (Departemen Pekerjaan Umum, Tanpa Tahun). Sistem manajemen K3 terdapat 
pada Undang-undang No. 1 Tahun 1970 tentang pentingnya jaminan kesehatan dan keselamatan bagi pekerja. Undang-undang ini menjadi acuan sebuah perusahaan dalam menerapkan K3 (Ernawati, 2010). Faktor penyebab kecelakaan kerja pada perusahaan antara lain dengan tidak memakai Alat Pelindung Diri (APD) (Sepang, 2013; Waruwu \& Yuamita, 2016). Aturan terhadap APD terdapat pada undang-undang No. 1 Tahun 1970 Tentang Keselamatan Kerja. Aturan ini tertulis bahwa pemberian APD pada karyawan harus diikuti dengan prosedur dasarnya, dilatih pemakaian APD, dan merawat APD (Waruwu \& Yuamita, 2016). APD yang wajib dikenakan oleh pekerja seperti pakaian pelindung (safety coverall/safety wearpack), safety body harness (tali keselamatan), safety shoes (sepatu pelindung kaki), safety helmet (alat pelindung kepala), safety goggles (kacamata pelindung), safety gloves (alat pelindung tangan), masker (alat pelindung pernafasan), ear plug (alat pelindung telinga), jaring polinet, jas hujan, rompi abu-abu, rompi biru, rompi hijau, rompi merah, dan rompi orens, safety deck (tudung pengaman), safety line (tali keselamatan), safety net (jaring pengaman), tali tambang plastik, dan trafic cone (kerucut lalu lintas) (Ira dkk, 2016).

Pengetahuan Keselamatan dan kesehatan kerja penting dimiliki oleh oleh para pekerja bangunan agar terhindar dari kecelakaan kerja baik yang diakibatkan oleh kelalaian manusia dan peralatan (Modul III Pengetahuan Dasar K3, 2016). Kelalaian manusia dan peralatan sebagai berikut: (1) pekerja kurang disiplin dalm mengikuti SOP; (2) kesadaran K3 pekerja bangunan rendah; (3) para pekerja bangunan terlalu percaya diri sehingga dikhawatirkan kebablasan (Ira dkk, 2016). K3 ditujukan untuk mencapai produktivitas yang optimal dan sangat penting untuk dilaksanakan pada semua bidang pekerjaan. Pelatihan K3 mampu menurunkan resiko kecelakaan kerja (Akpan, 2011; Smith \& Sonesh, 2011; \& Waruwu \& Yuamita, 2016). Pelatihan K3 merupakan salah satu faktor yang menjadi kontrol atas tindakan tidak aman yang dilakukan oleh para pekerja (Murti, 2015). Melalui pelatihan K3 para pekerja bangunan diharapkan dapat menyempurnakan pengalaman dengan memadukan pengetahuan K3 sehingga dapat meningkatkan kesehatan dan keselamatan kerja (Murtinugraha \& Anisah, 2019). Dengan demikian sebagai berikut: (1) kualitas dunia konstruksi dapat dilihat dari tenaga kerja yang bebas kecelakaan; (2) manajemen K3 dibutuhkan di setiap perusahaan; (3) tenaga kerja perlu dilindungi; (4) tenaga kerja di Indonesia mempuyai pengetahuan K3 yang cenderung masih rendah; (5) dunia konstruksi di Indonesia penyumbang terbesar kecelakaan kerja; (6) kecelakaan kerja bisa dikendalikan dengan K3; (7) sistem K3 terdapat pada Undang-undang No. 1 Tahun 1970 dan APD ada dalam aturan ini; (8) pengetahuan K3 penting dimiliki oleh para pekerja bangunan agar meningkatkan kesehatan dan keselamatan kerja.

Dalam uraian di atas disebutkan bahwa pengetahuan para pekerja bangunan di Indonesia cenderung masih rendah. Hal ini senada juga dengan para pekerja bangunan di kedua mitra pengabdian ini yaitu RT 05 dan RW 06. Kedua mitra ini terletak di Jl. Durian Dalam, Kelurahan Wuawua, Kecamatan Wuawua, Kota Kendari. Masyarakat di kedua mitra ini banyak berprofesi sebagai tukang bangunan, tukang ojek, dan tukang gali sumur. Berdasarkan hasil observasi tim pengabdi bahwa para pekerja bangunan di kedua mitra tersebut pada saat mendirikan bangunan tidak melengkapi diri dengan APD (Gambar 1). Hal ini disebabkan sebagai berikut: (1) para pekerja bangunan di kedua mitra tidak mengetahui K3; (2) kesadaran terhadap pentingnya APD cenderung masuh rendah; (3) para pekerja bangunan sudah terbiasa tidak menggunakan APD; (4) mindset para tukang bangunan bahwa APD merupakan barang mewah dan biaya tinggi sehingga dengan menggunakan APD pada saat mendirikan bangunan identik dengan tidak ekonomis.

Mindset inilah yang perlu diubah oleh para tukang bangunan di kedua mitra tersebut. Dengan menggunakan APD pada saat mendirikan bangunan justru pekerjaan menjadi ekonomis, sehat, dan aman. Sebagai contoh seorang tukang bangunan mendirikan bangunan tanpa menggunakan APD dan tiba-tiba mengalami gangguan kesehatan maka pekerja bangunan tersebut akan kehilangan upah dalam beberapa hari ke depan. Selain upah kerja per hari, biaya pengobatan di rumah sakit juga cenderung biaya tinggi. Oleh karena itu, permasalahan ini menjadi tanggung jawab tim pengabdi dari Program Studi D3 Teknik Arsitektur, Program 
Pendidikan Vokasi, Universitas Halu Oleo. Melalui bantuan Penelitian dan Pengabdian Terapan untuk dosen homebase Program Pendidikan Vokasi, tim pengabdi ingin memberi bimbingan teknis K3 pada tukang bangunan lokal pada kedua mitra tersebut.

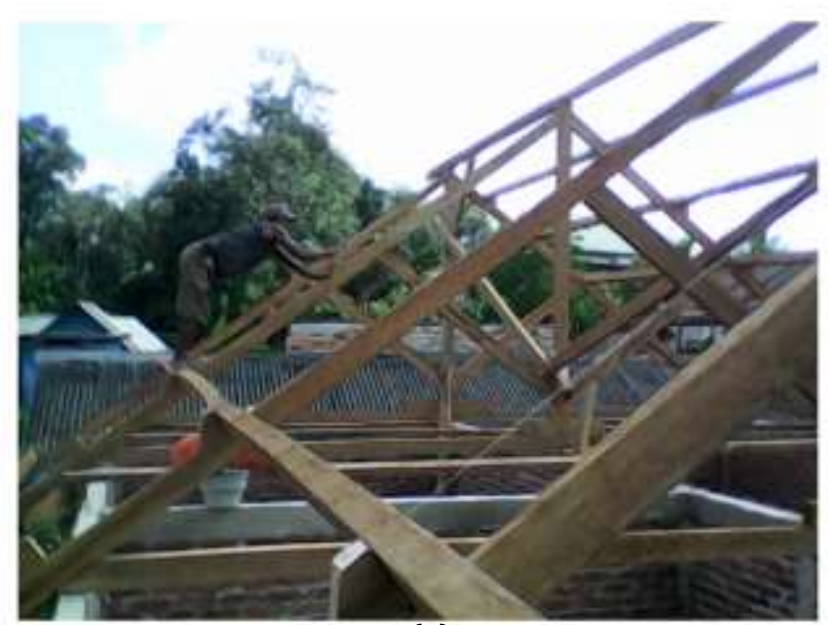

(a)

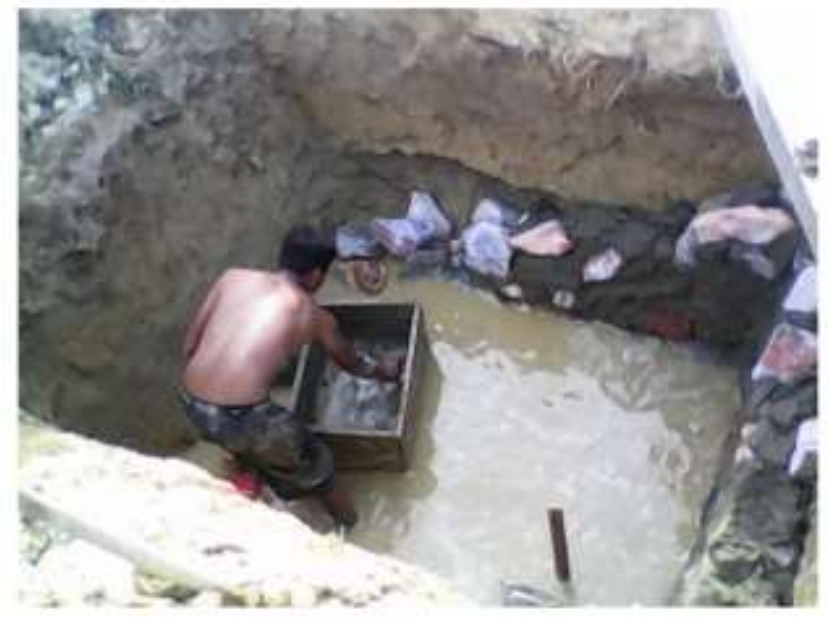

(b)

Gambar 1. Tukang bangunan di RT 05 merangkai konstruksi rangka atap tanpa menggunakan APD (Gambar 1a) dan tukang bangunan di RT 06 menyusun pasang batu septic tank dengan tidak menggunakan pakaian (Gambar 1b) (Sumber: Muhammad Zakaria Umar, 2020)

Pengabdian ini penting dilaksanakan sebagai berikut: (1) agar para pekerja bangunan di kedua mitra mempunyai kesadaran K3 yang baik khususnya terkait APD; (2) para pekerja bangunan di kedua mitra tersebut cenderung masih rendah terkait K3 sehingga dikhawatirkan tentang keselamatan dan kesehatannya. Dengan pengabdian ini, tim pengabdi mempunyai harapan-harapan sebegai berikut: (1) para mitra mempunyai kesadaran K3 dari sisi ekonomi bahwa dengan memahami K3 maka pendapatan tidak akan berkurang bahkan bertambah; (2) para mitra mempunyai kesadaran K3 dari sisi kesehatan bahwa selain menjaga kesehatan diri sendiri juga dapat menjaga kesehatan rekan-rekan kerja; (3) para mitra mempunyai kesadaran K3 dari sisi perusahaan bahwa dengan memahami K3 maka para pekerja bangunan turut menjaga perusahaan tempat bekerja karena tidak menjadi beban perusahaan; (4) para mitra mempunyai kesadaran K3 dari sisi keluarga di rumah bahwa dengan memahami K3 maka para pekerja bangunan juga menjaga keluarga di rumah sehingga semuanya selalu dalam keadaan sehat serta aman. 


\section{METODE}

Pengabdian ini menggunakan metode penyuluhan dan praktik. Permasalahan spesifik yang dihadapi oleh kedua mitra adalah kesadaran K3 kedua mitra cenderung masih rendah. Oleh karena itu dibutuhkan bimbingan teknis K3 pada tukang bangunan lokal di kedua mitra tersebut dari tim pengabdi Prodi D3 Teknik Arsitektur, PPV-UHO. Tahap-tahapan persiapan sebagai berikut: (1) pemilihan dosen yang berkompeten pada bidang masing-masing dan pemilihan para mahasiswa Prodi D3 Teknik Arsitektur; (2) persiapan prasarana seperti koordinasi dengan tim pengabdi bimbingan teknis K3, berkoordinasi dengan Kelurahan Wuawua, dan berkoordinasi dengan para Ketua RT setempat. Tim pelaksana kegiatan ini terdiri dari enam rekan-rekan dosen dan empat rekan-rekan mahasiswa. Spesifikasi satu sebagai ketua tim yang berkompeten di bidang K3, anggota satu berkompeten di bidang perancangan kota dan permukiman, anggota dua berkompeten dibidang konstruksi bangunan, anggota tiga berkompeten di bidang kewirausahaan, anggota empat berkompeten di bidang perencanaan wilayah, dan anggota lima berkompeten di bidang teknologi informasi. Kegiatan ini juga melibatkan empat rekan-rekan mahasiswa angkatan 2018 dan 2019 pada Program Studi D3 Teknik Arsitektur, PPV-UHO. Kriteria-kriteria mahasiswa yang dilibatkan antara lain telah lulus mata kuliah K3 dan konstruksi bangunan.

Sebelum melaksanakan kegiatan ini para dosen dibekali sebagai berikut: (a) kemampuan untuk mengidentifikasi APD K3; (b) kemampuan untuk menggunakan APD dengan baik; (c) kemampuan untuk mengidentifikasi fungsi-fungsi masing-masing APD; (d) kemampuan membuat soal-soal pra tes dan pos tes serta; (3) kemampuan untuk membuat power point terkait K3. Para mahasiswa juga dibekali dengan teknis pelaksanaan pra tes, administrasi pada saat prates dan postes, pendokumentasian kegiatan, dan teknik-teknik melayani masyarakat dengan baik. Pada tahap pertama dilakukan kegiatan urun rembuk terkait perkenalan para dosen pengabdi dan para mahasiswa, tujuan kegiatan, dan program-program kegiatan kepada para ketua RT setempat agar memiliki persepsi yang sama. Tahap kedua diadakan penjelasan terkait bimbingan teknis dan penyusunan jadwal kegiatan. Tahap ketiga adalah tahap prates.

Prates ditujukan untuk mengetahui pengetahuan awal terkait K3. Tahap keempat melaksanakan praktik pemakaian alat-alat K3, foto-foto akibat tidak menggunakan APD, dan fungsi-fungsi APD tersebut. Tahap kelima ditutup dengan postes. Postes ditujukan untuk mengetahui tingkat pemahaman tukang bangunan terkait semua materi kegiatan yang telah diberikan. Nilai prates dan nilai postes dibuatkan tabel, dihitung nilai rata-ratanya, dan dibandingkan. Nilai prates dan nilai postes dibuatkan diagram batang sehingga terlihat perbedaan nilai-nilai tersebut. Selain dianalisis dengan diagram batang, perbedaan nilai juga diuji dengan analisis uji tanda agar perbedaan nilai tersebut lebih valid. Perbedaan nilai-nilai tersebut juga memperlihatkan peningkatan pengetahuan baik sebelum dan sesudah materi K3 diberikan.

\section{HASIL DAN PEMBAHASAN}

Pengabdian tentang K3 ini dilaksanakan selama hampir satu bulan. Kegiatan ini dimulai dari Bulan November sampai dengan Desember Tahun 2020. Pelaksanaan pengbadian tentang K3 ini tediri dari empat sesi. Sesi pertama adalah prates. Sesi kedua adalah penyuluhan. Sesi ketiga adalah praktik. Sedangkan sesi keempat adalah postes. Keempat sesi-sesi tersebut ditujukan agar pengabdian ini dapat terlihat keberhasilannya terkait transfer pengetahuan tentang K3 pada tukang bangunan. Keempat sesi-sesi tersebut dijelaskan di bawah ini. 


\subsection{Sesi Prates}

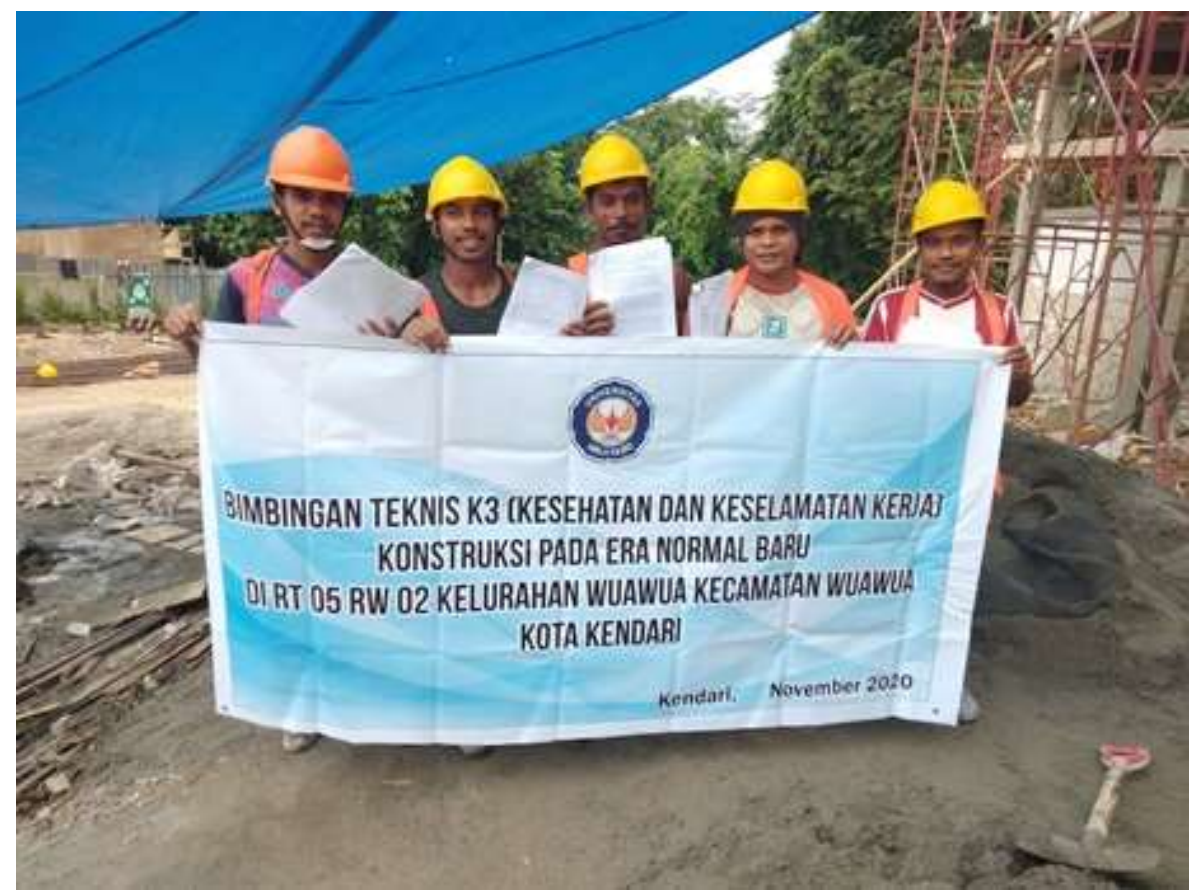

Gambar 2. Para peserta tukang bangunan berswafoto sebelum prates dilaksanakan (Sumber: Muhammad Zakaria Umar, 2020)

Sesi prates dilaksanakan pada Hari Sabtu tanggal 21 November 2020 dan pelaksanaannya pada jam 10.00 WITA sd selesai. Sesi prates adalah tahap pertama yang dilaksanakan dalam pengabdian K3 ini. Sesi prates ditujukan untuk mengetahui pengetahuan K3 tukang bangunan sebelum dilaksanakannya pengabdian ini, sehingga tim pengabdi dapat mengukur sampai sejauh mana pemahaman para tukang bangunan terkait K3. Sesi prates sangat penting dilaksanakan karena dengan prates tim pengabdi dapat memberikan strategi-strategi terkait K3 pada saat penyuluhan nanti (Gambar 2).

Sesi prates sangat bermanfaat juga bagi para tukang bangunan karena dengan menjawab soal-soal sesi satu otomatis para tukang bangunan juga akan belajar mengenai K3. Sesi prates terdiri dari dari lima sesi. Kelima sesi tersebut terbagi lagi dalam beberapa sub-sub sesi. Sub-sub sesi tersebut sebagai berikut: (1) sesi satu adalah soal uraian mengisi; (2) sesi dua adalah pilhan ganda; (3) sesi ketiga adalah pilihan benar atau salah; (4) sesi kempat adalah pilihan benar atau salah; (5) dan sesi lima adalah soal-soal uraian mengisi.

Soal-soal sesi pertama membahas terkait latar belakang K3, pentingnya K3, tujuan K3, dan manfaat K3 bagi para tukang bangunan. Soal-soal sesi kedua membahas tentang risikorisiko keselamatan bagi para tukang bangunan, jenis-jenis alat pelindung diri, dan cara kerja yang aman. Soal-soal sesi ketiga membahas tentang risiko-risiko keeshatan dan keselamatan (kulit, mata, alergi, dan pernafasan), manfaat alat pelindung diri, dan penggunaan tangga yang aman. Soal-soal sesi keempat membahas tenatng penggunaan tangga yanga aman, bahaya kejut listrik, dan ergonomi.

Soal-soal sesi kelima membahas terkait penerapan K3 pada bangunan, proses kerja pada saat membangun, bahaya potensial pada saat membangun, asuransi kesehatan bagi tukang bangunan yang mengalami kecelakaan kerja, dan solusi jika perusahaan yang tidak menyediakan Alat Pelindung Diri (APD). Masing-masing sesi diberi nilai dan bila dibobot maka akan berjumlah seratus. Masing-masing sesi mempunyai nilai seperti sesi satu bernilai lima belas, sesi dua bernilai lima belas, sesi tiga bernilai dua puluh, sesi empat bernilai dua puluh, dan sesi lima bernilai tiga puluh. 


\subsection{Sesi Penyuluhan}

Setelah sesi prates telah selesai dilaksanakan maka dilanjutkan langsung sesi penyuluhan. Sesi penyuluhan ditujukan fokus untuk membahas terkait soal-soal prates secara mendalam dan memberikan penegtahuan K3 sesuai dengan kebutuhan para tukang bangunan. Sesi penyuluhan dipresentasikan dalam bentuk aplikasi power point. Para tukang bangunan juga diberi penjelasan dengan bahasa yang bersahaja sehingga materi yang diberikan mudah dicerna dengan baik. Sesi penyuluhan sangat bermanfaat bagi parav tukang bangunan sebagai berikut: (1) pada sesi inilah desiminasi dan transfer pengetahuan antara tim pengabdi dan para tukang bangunan terlaksana; (2) pada sesi ini juga akan memberikan pengantar sebelum praktik menggunakan APD (Gambar 3).

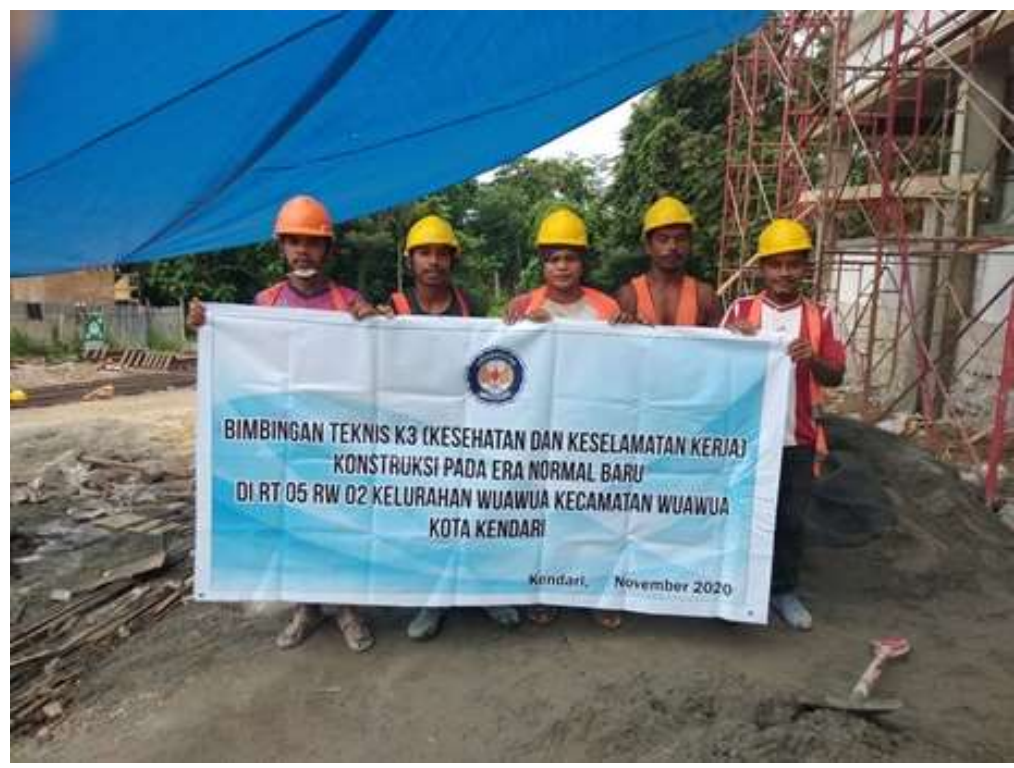

Gambar 3. Para peserta tukang bangunan berswafoto setelah sesi penyuluhan telah selesai dilaksanakan (Sumber: Muhammad Zakaria Umar, 2020)

\subsection{Sesi Praktik}

Sesi praktik dilaksanakan pada Hari Minggu tanggal 6 Desember 2020. Kegiatan ini dilaksanakan pada pukul 09.00 WITA sd selesai. Kegiatan praktik ini hanya diikuti oleh lima orang tukang bangunan saja karena suasana masa pandemi. Sesi praktik ini dilakukan dengan cara satu orang tukang bangunan menggunakan APD lengkap yang sesuai dengan kebutuhan para tukang bangunan. Sesi praktik ini ditujukan untuk mengajarkan para tukang bangunan menggunakan APD dengan tepat. APD tersebut sudah disediakan oleh tim pengabdi seperti sepatu boot safety, kaos kaki, sarung tangan, masker, safety helmet, dan rompi polyester orange. Pemakaian APD diarahkan langsung oleh tim pengabdi. APD yang pertama kali dipakai oleh tukang bangunan adalah kaos kaki, sepatu boot, rompi polyester orange, helem, masker, dan terakhir sarung tangan.

Foto-foto tukang bangunan menggunakan APD lengkap yang sesuai dengan materi yang telah dipelajari dapat di lihat pada gambar di atas ini (Gambar 4). Kaos kaki safety ini tebal dan berbahan spandek anti bakteri. Kaos kaki ini mempunyai nafas uap sehingga kaki terlindungi dari pengap dan bau. Kaos kaki adalah pelengkap yang sangat penting bagi para tukang bangunan agar kaki nyaman di dalam sepatu. Satu pasang kaos kaki safety didapatkan dengan harga Rp. 50.000,- (lima puluh ribu rupiah). Sepatu karet boots safety berfungsi mengamankan kaki dari benda-benda tajam, seperti pecahan kaca, besi, dan kayu. Sepatu ini sangat membantu para pekerja untuk melindungi kaki dari risiko kecelakaan kerja. Sepatu karet boot safety berbahan karet. Sepatu boot safety bisa didapatkan dengan harga Rp. 80.000,- (delapan puluh ribu rupiah). Sarung tangan safety berfungsi sebagai alat pelindung tangan saat bekerja di tempat atau kondisi yang dapat mengakibatkan cedera tangan. 


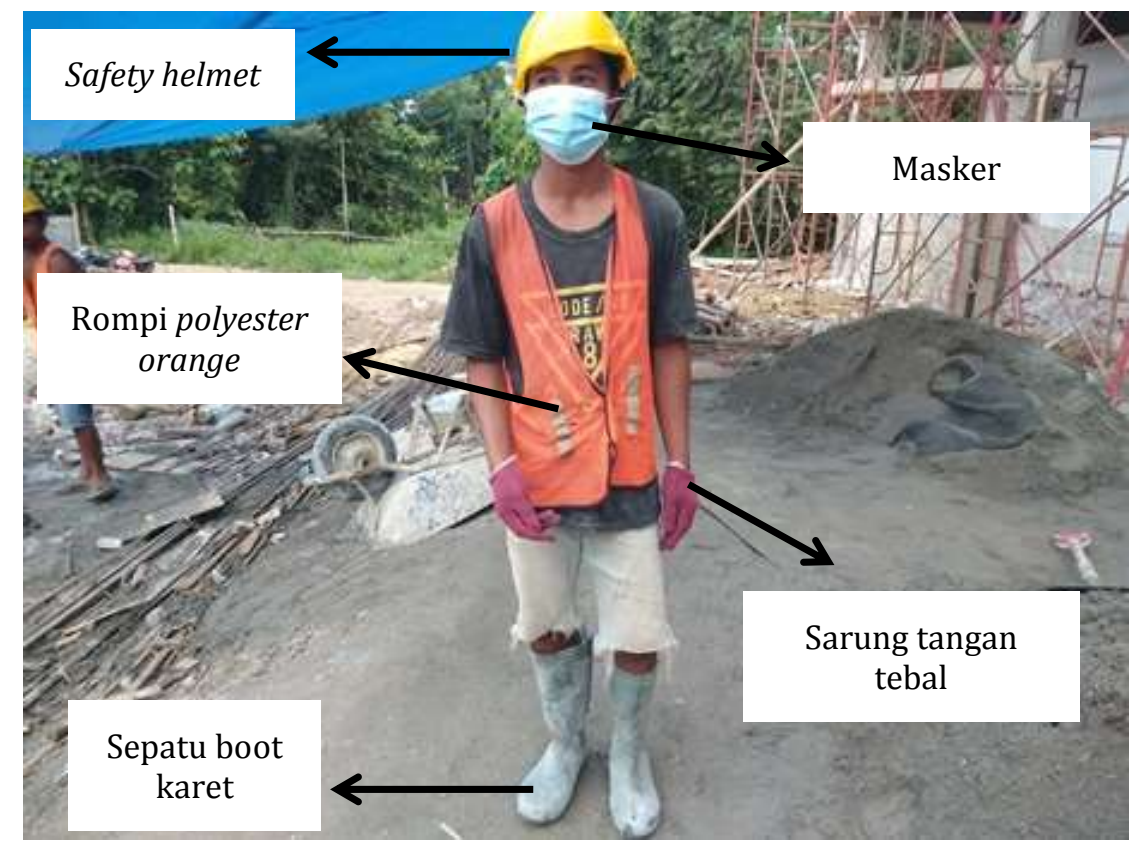

Gambar 4. Salah seorang tukang bangunan menggunakan APD lengkap pada saat mendirikan bangunan (Sumber: Muhammad Zakaria Umar, 2020)

Bahan dan bentuk sarung tangan disesuaikan dengan fungsi masing-masing pekerjaan. Pada gambar di atas tukang bangunan menggunakan sarung tangan berbahan benang wol tebal. Sarung tangan safety bisa didapatkan dengan harga Rp. 5.000,- (lima ribu rupiah). APD masker berfungsi untuk menyaring udara yang akan dihirup pada saat bekerja sehingga tidak membahayakan pernapasan. Masker safety memiliki tiga lapisan. Lapisan pertama adalah lapisan luar kain tanpa anyaman kedap air. Lapisan dalam adalah lapisan filter densitas tinggi. Masker safety bisa didapatkan dengan harga Rp. 10.000,- (Sepuluh ribu rupiah). Safety helmet terbuat dari kombinasi material plastik khusus yang memiliki sifat tahan benturan.

APD Safety helmet berfungsi untuk melindungi kepala dari bahaya seperti kejatuhan bendabenda, terbentur benda keras yang dapat membahayakan kepala saat bekerja. Safety helmet mampu melindungi kepala dari risiko cedera akibat terjadinya benturan keras dan terkena jatuhan benda tajam. Safety helmet bisa didapatkan dengan harga Rp. 50.000,- (lima puluh ribu rupiah). Rompi safety adalah salah satu APD yang terbuat dari bahan polyester yang dirancang khusus serta dilengkapi dengan pemantul cahaya. Rompi safety dapat digunakan pada siang atau pun malam hari. Rompi safety berfungsi untuk mencegah terjadinya kontak kecelakaan pada pekerja. Rompi polyester orange terbuat dari bahan polyester, jaring WP, doble mess, parasut, biway. resleting, dan scotlight. Rompi safety bisa didapatkan dnegan harga Rp. 20.000,- (Dua puluh ribu rupiah).

\subsection{Sesi Postes}

Tabel 3. Hasil Prates dan Postes Peserta Kegiatan

\begin{tabular}{llccccc}
\hline No. & Nama & Pekerjaan & Alamat & $\begin{array}{c}\text { Nilai } \\
\text { Pratest }\end{array}$ & $\begin{array}{c}\text { Nilai } \\
\text { Postest }\end{array}$ & $\begin{array}{c}\text { Peningkatan } \\
\text { Pengetahuan }\end{array}$ \\
\hline 1. & Joko & Tukang bangunan & RT 05 RW 02 & 35 & 85 & 50 \\
2 & Abu & Tukang bangunan & RT 05 RW 02 & 40 & 80 & 40 \\
3 & Emen & Tukang bangunan & RT 06 RW 02 & 25 & 85 & 60 \\
4 & Luke & Tukang bangunan & RT 06 RW 02 & 30 & 90 & 60 \\
5. & Ajir & Tukang bangunan & RT 06 RW 02 & 50 & 90 & 40 \\
Rata-rata & & & 36 & 86 & 50 \\
\hline
\end{tabular}

Sesi postes dilaksanakan setelah dan bersamaan dengan sesi penyuluhan. Sesi postes ini dilaksanakan pada siang hari dan bertepatan dengan waktu para tukang bangunan beristirahat. Sesi postes ditujukan untuk mengukur apakah pengetahuan para tukang bangunan tentang K3 
meningkat atau tidak meningkat setelah bimbingan teknis. Sesi postes juga ditujukan untuk mengevaluasi seluruh kegiatan terkait apa yang perlu ditambahkan dan apa yang perlu dikurangi terkait materi pengabdian ini. Sesi postes ini sangat bermanfaat buat para tukang bangunan karena pada sesi ini secara otomatis para tukang bangunan mengulang seluruh materi kegiatan sehingga diharapkan lebih menguasai materi K3. Sesi postes dilaksanakan sama dengan sesi prates yaitu dengan mengisi soal-soal pembelajaran. Soal-soal postes dibuat sama dengan soal-soal prates sehingga mudah disandingkan dan terlihat rata-rata perbedaan nilainilainya. Nilai prates terendah adalah 25. Nilai prates tertinggi adalah 50 . Rata-rata nilai prates adalah 36. Nilai postes terendah adalah 80. Nilai postes tertinggi adalah 90. Rata-rata nilai postes adalah 86. Nilai peningkatan pengetahuan terendah adalah 40 , nilai peningkatan pengetahuan tertinggi adalah 60 , dan rata-rata peningkatan pengetahuan adalah 50 (Tabel 3).

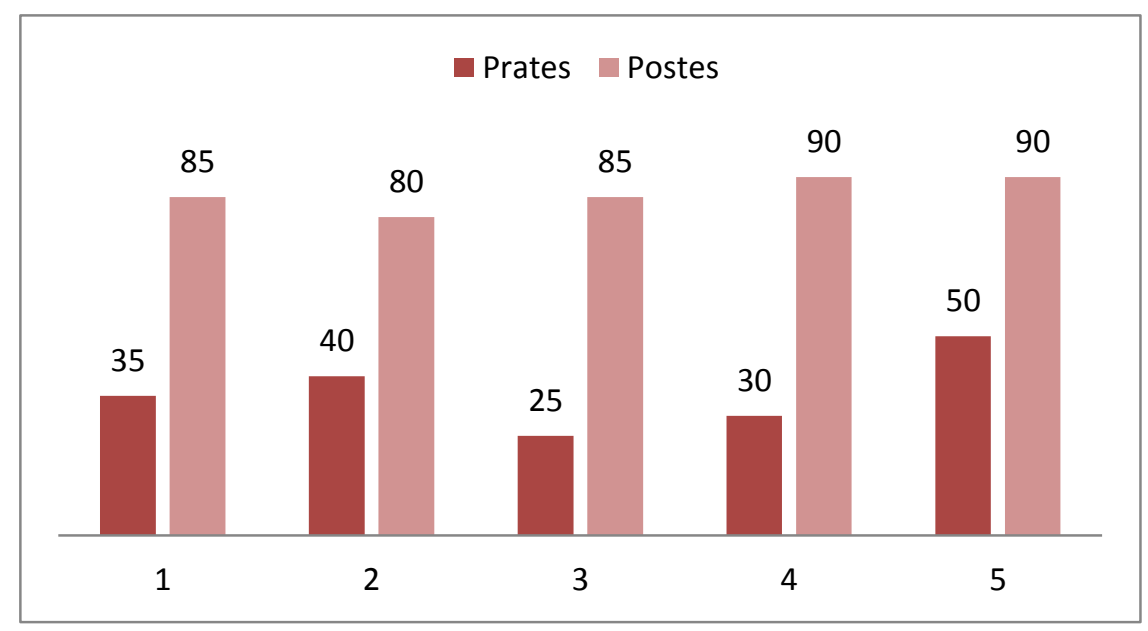

Gambar 5. Analisis komparasi nilai prates dan postes.

\subsection{Analisis Komparasi Nilai Prates dan Nilai Postes}

Berdasarkan hasil analisis komparasi pada diagram batang di bawah bahwa nilai postes lebih tinggi dibandingkan dengan nilai prates (Gambar 5). Nilai postes lebih tinggi dibandingkan dengan nilai prates karena sebangai berikut: (1) materi K3 yang telah diberikan oleh tim pengabdi telah dipahami dengan baik oleh para tukang bangunan; (2) para tukang bangunan telah menggunakan APD yang lengkap pada saat mendirikan bangunan.

\subsection{Uji Tanda $N$ Par Tests}

Berdasarkan hasil analisis uji tanda (Sign Test) di atas, pada baris Negative Differences dapat diperoleh bahwa banyaknya data (N) sebanyak 0 data yang menunjukan tidak ada nilai pada Postest yang lebih kecil dari nilai pretest. Pada baris Positive Differences dapat diperoleh bahwa banyaknya data $(\mathrm{N})$ sebanyak 5 data yang menunjukan nilai pada Postest yang lebih besar dari nilai pretest, pada baris Ties dapat diperoleh bahwa banyaknya data $(\mathrm{N})$ sebanyak 0 data yang menunjukan tidak ada nilai pada Postest yang sama dengan nilai pretest dengan total data yang di analisis sebanyak 5 data.

Berdasarkan hasil analisis (Test Statistics) di peroleh bahwa nilai Exact Sig. (2-tailed) sebesar 0,31 yang di peroleh dari distribusi binomial.

Hipotesis:

H0 : Tidak ada perbedaan antara nilai pada data sebelum dan data sesudah penyuluhan

$\mathrm{H} 1$ : Ada perbedaan antara nilai pada data sebelum dan data sesudah penyuluhan

Kriteria Uji:

Terima H0 jika nilai Exact Sig. (2-tailed) $>\alpha(0,05)$

Tolak H0 jika nilai Exact Sig. (2-tailed) $<\alpha(0,05)$

Taraf Signifikan:

Taraf signifikan yang digunakan sebesar 5\% 
Berdasarkan hasil analisis di atas (Test Statistics) diperoleh bahwa nilai Exact Sig. (2tailed) sebesar $0,31<$ dari $\alpha(0,05)$ yang artinya H0 ditolak. Sehingga dapat disimpulkan bahwa ada perbedaan antara nilai pada data sebelum dan data sesudah penyuluhan.

\section{KESIMPULAN}

Berdasarkan hasil analisis di atas, pengabdian ini disimpulkan bahwa pengetahuan tukang bangunan meningkat baik sebelum dan sesudah bimbingan teknik karena karena nilai postes lebih tinggi dibandingkan dengan nilai prates.

\section{DAFTAR PUSTAKA}

Akpan, E., I. (2011). Effective Safety and Health Management Policy for Improved Performance of Organizations in Africa. International Journal of Business and Management, University of Calabar, Nigeria, 6(3).

Bahri, S., Purwanto, \& Syahputra, Z. (2017). Keselamatan dan Kesehatan Kerja (K3) pada Pembangunan pada Proyek Pembangunan Kantor Yonzipur dan Jalan di Makroman Samarinda. Teknik Sipil dan Arsitektur, 1(1), 1-8.

Departemen Pekerjaan Umum. (Tanpa Tahun). Pelatihan Ahli K3 Konstruksi. Pembinaan Konstruksi dan Sumber Daya Manusia Pusat Pembinaan Kompetensi dan Pelatihan Konstruksi. Diakses tanggal 11 September 2020 dari https://bit.ly/2Ft7w4M

Ernawati, A. (2010). Peningkatan Keahlian Tukang Bangunan Guna Menunjang Program K3 dan ISO 9002 dalam Bidang Pekerjaan Jasa Konstruksi. Jurnal Ilmiah Faktor Exacta, 3(3), 287297.

Hardianingtyas, P. (2011). Laporan Khusus Pelaksanaan Training K3 sebagai Upaya Mencapai Zero Accident di PT. Sari Husada Unit I Yogyakarta. Program Diploma III Hiperkes dan Keselamatan Kerja, Fakultas Kedokteran Universitas Sebelas Maret, Surakarta.

Ira, N., P., Mulyani, E., \& Nuh, E., S., M. (2016). Penerapan Program K3 pada Pembangunan Gedung Tinggi di Kota Pontianak. Jurnal Mahasiswa Teknik Sipil Universitas Tanjungpura, 1(1), 1-12.

Modul III Pengetahuan Dasar K3. (2016). Diklat Sistem Manajemen Keselamatan Kesehatan Kerja Konstruksi Tingkat Dasar Kementerian Pekerjaan Umum dan Perumahan Rakyat. Badan Pengembangan Sumber Daya Manusia Pusat Pendidikan dan Pelatihan Sumber Daya Air dan Konstruksi, Bandung, 1-70.

Murti, A., K. (2015). Analisis Hubungan Antara Pelatihan Keselamatan dan Kesehatan Kerja dengan Perilaku Aman pada Pekerja Konstruksi. Penerbit: UAJY, Sleman, Daerah Istimewa Yogyakarta.

Murtinugraha, R., E., \& Anisah. (2019). Peningkatan Pemahaman K3 Pekerjaan Konstruksi bagi Tukang Bangunan di Kecamatan Muara Gembong, Kabupaten Bekasi. JPkM: Jurnal Pengabdian kepada Masyarakat, 1(1), 62-72.

Sepang, B., A., W. (2013). Manajemen Risiko Keselamatan dan Kesehatan Kerja (K3) pada Proyek Pembangunan Ruko Orlens Fashion Manado. Jurnal Sipil Statik, 1(4), 282-288.

Smith, A., \& Sonesh, S. (2011). How Hazards and Safety Training Influence Learning and Performance. Journal of Applied Psychology 2011 American Psychological Association, 96(1), 46-70.

Waruwu, S., \& Yuamita, F. (2016). Analisis Faktor Kesehatan dan Keselamatan Kerja (K3) yang Signifikan Mempengaruhi Kecelakaan Kerja pada Proyek Pembangunan Apartement Student Castle. Spektrum Industri, 14(1), 63-78.

Woodside, G., \& Kocurek, D. (1951). Environmental, Safety, and Health Engineering. New York: John Wiley \& Sons Inc. 